University of Nebraska - Lincoln

DigitalCommons@University of Nebraska - Lincoln

Faculty Publications from the Harold W. Manter Laboratory of Parasitology

$10-2003$

\title{
Two Species of Acuaria Bremser, 1811 (Nematoda: Acuarioidea: Acuariidae) in Passerine Birds from the Área de Conservación Guanacaste, Costa Rica
}

\author{
Luping Zhang \\ University of Toronto \\ Daniel R. Brooks \\ University of Toronto, dnlbrooks@gmail.com \\ Douglas Causey \\ University of Alaska Anchorage, dcausey@uaa.alaska.edu
}

Follow this and additional works at: https://digitalcommons.unl.edu/parasitologyfacpubs

Part of the Parasitology Commons

Zhang, Luping; Brooks, Daniel R.; and Causey, Douglas, "Two Species of Acuaria Bremser, 1811 (Nematoda: Acuarioidea: Acuariidae) in Passerine Birds from the Área de Conservación Guanacaste, Costa Rica" (2003). Faculty Publications from the Harold W. Manter Laboratory of Parasitology. 234. https://digitalcommons.unl.edu/parasitologyfacpubs/234

This Article is brought to you for free and open access by the Parasitology, Harold W. Manter Laboratory of at DigitalCommons@University of Nebraska - Lincoln. It has been accepted for inclusion in Faculty Publications from the Harold W. Manter Laboratory of Parasitology by an authorized administrator of DigitalCommons@University of Nebraska - Lincoln. 


\title{
TWO SPECIES OF ACUARIA BREMSER, 1811 (NEMATODA: ACUARIOIDEA: ACUARIIDAE) IN PASSERINE BIRDS FROM THE AREA DE CONSERVACION GUANACASTE, COSTA RICA
}

\author{
Luping Zhang, Daniel R. Brooks*, and Douglas Causey $†$ \\ Department of Zoology, University of Toronto, Ontario, Canada M5S 3G5. e-mail: dbrooks@zoo.utoronto.ca
}

\begin{abstract}
Two species of Acuaria were collected from passerine birds from the Area de Conservacion Guanacaste, Costa Rica. Acuaria mayori Lent, Freitas and Proenca, 1945, was collected from Myiarchus nuttingi. Specimens from Costa Rica differ from the original description by having a spicule ratio of 1:1.5-1.7 versus $1: 1.43-1.47$, as well as shorter spicules and female tails. Acuaria wangi $\mathrm{n}$. sp. in Hylophylax naevioides and Gymnopithys leucaspis resembles A. alii, A. crami, A. cyanocitta, A. minuta, A. pattoni, and A. cissae by having cordons extending posteriorly to the anterior portion of the glandular esophagus. The new species differs from $A$. alii by having 4 pairs of preanal and 6 pairs of postanal papillae rather than 2 pairs of preanal and 7 pairs of postanal papillae, a shorter left spicule, a spicule ratio of 1:1.6-1.8 versus 1:1.1 and in having spicules with blunt rather than pointed distal ends. Acuaria crami and A. minuta differ from A. wangi by having 7 pairs of postanal papillae and spicule ratios of $1: 1.6-1.8$ versus $1: 1.3$ in $A$. crami and 1:1.1 in A. minuta; in addition, $A$. minuta has spatulate-shaped spicules and a tricupsid-shaped distal end of the right spicule. The new species can be distinguished from A. pattoni by having a longer left spicule and a spicule ratio of 1:1.6-1.8 versus $1: 1$ and from $A$. cissae by having a shorter left spicule and a spicule ratio of 1 : 1.6-1.8 versus $1: 2.5-2.7$. Acuaria wangi is similar to A. cyanocitta, which has similarly shaped spicules, including a very pointed distal end of the left spicule, but differs in body length, in having shorter spicules, in the arrangement of postanal papillae, and in having smaller eggs.
\end{abstract}

Acuaria Bremser, 1811, is the most species-rich genus of acuariid nematodes, with more than 70 nominal species (Sherwin and Schmidt, 1988). All but 1 known species inhabit passerine birds, the exception being A. upupa Rasheed, 1960, from the coraciiform bird, Upupa epops, from India (Mawson, 1972). Bremser (1811) proposed Acuaria without designating a type species. Of the 14 species he included in Acuaria, Spiroptera anthuris Rudolphi, 1819, is regarded as the type species for Anthuris Rudolphi, 1819, by absolute tautonomy and by $\mathrm{Ru}-$ dolphi's original intentions, but Rudolphi admitted that Anthuris was Acuaria Bremser, 1811, renamed; hence, the type species A. anthuris is the type species of Acuaria (Cram, 1927). Skrjabin et al. (1965) regarded Cheilospirura Diesing, 1861, as a synonym of Acuaria, but Chabaud (1975) considered Cheilospirura a valid genus.

During June 2001 and January 2002, as part of an ongoing biodiversity inventory of the eukaryotic parasites of vertebrates inhabiting the Area de Conservacion Guanacaste (ACG) in northwestern Costa Rica (http://brooksweb.zoo.utoronto.ca/ index.html), 2 species of Acuaria were collected from passerine birds. We describe both in this article.

\section{MATERIALS AND METHODS}

Nutting's flycatchers, Myiarchus nuttingi Ridgway, $1883(\mathrm{n}=5)$, spotted antbirds, Hylophylax naevioides (Lafresnaye, 1847) $(\mathrm{n}=23)$, and bicolored antbirds, Gymnopithys leucaspis (Sclater, 1885) $(\mathrm{n}=7)$ were collected in June 2001 and January 2002 and examined for parasites. Nematodes collected from beneath the lining of the gizzard were fixed in glacial acetic acid and preserved in $70 \%$ ethanol. They were later cleared in lactophenol for further examination. Drawings were made with the aid of a drawing tube. Measurements (range, followed by mean in parentheses) are given in micrometers unless otherwise stated.

Received 9 December 2002; revised 7 April 2003; accepted 7 April 2003.

* To whom correspondence should be addressed.

† Museum of Comparative Zoology, Harvard University, Cambridge, Massachusetts.

\section{DESCRIPTION}

\section{Acuaria mayori Lent, Freitas and Proenca, 1945}

(Figs. 1-6)

Diagnosis: Body small with transverse striations. Two pseudolabia lateral to mouth, each bearing a pair of large cephalic papillae and 1 inconspicuous amphid. Cordons straight, nonanastomosing, and nonrecurrent, originating at dorsal and ventral sides of oral opening, continuing posteriorly to middle of muscular esophagus, $3.2-4.8 \%(4.0 \%)$ total body length (TBL) in male and $1.9-2.7 \%(2.4 \%)$ TBL in female. Buccal capsule long and slender, transversely striated. Esophagus clearly divided into short anterior muscular part and long posterior glandular part. Muscular esophagus $4.0-5.6 \%(5.2 \%)$ TBL in male and $2.2-3.4 \%(2.7 \%)$ TBL in female; glandular esophagus $9.8-$ $12.7 \%(11.4 \%)$ TBL in male and $4.8-5.8 \%(5.2 \%)$ TBL in female. Nerve ring located at the level of the anterior end of the muscular esophagus. Cervical papillae located at the same level as nerve ring. Excretory pore immediately posterior to nerve ring.

Male $(n=7)$ : Body length 5.427-7.452 mm $(6.808 \mathrm{~mm})$. Maximum width 111-148 (131). Cordons 239-323 (275) long. Buccal capsule 114-156 (134) long. Muscular esophagus 266429 (355) long and 30-38 (34) wide; glandular esophagus 646893 (778) long and 49-61 (56) wide. Nerve ring 171-209 (188) from anterior end, excretory pore 255-289 (268) from anterior end, and cervical papillae 167-213 (188) from anterior end. Posterior end of body curved. Caudal alae well developed, 311396 (348) long, and 38-60 (48) wide. Tail bluntly rounded, 162-178 (169) long. Eleven pairs of caudal papillae, 4 pairs preanal and 7 pairs postanal. Spicules subequal and similar, with rounded distal end. Left spicule 163-186 (179) long, 12.916.1 (15.9) wide at base of proximal end. Right spicule 102123 (111) long, 12.9-19.3 (16.1) wide at base of proximal end. Ratio of right spicule-left spicule 1:1.5-1.7 (1:1.6).

Female $(n=7)$ : Body length $13.84-22.03 \mathrm{~mm}(18.74 \mathrm{~mm})$. Maximum width 163-192 (173). Cordons 368-518 (444) long. Buccal capsule 143-182 (159) long. Muscular esophagus 441597 (509) long and 32-57 (45) wide; glandular esophagus 799- 

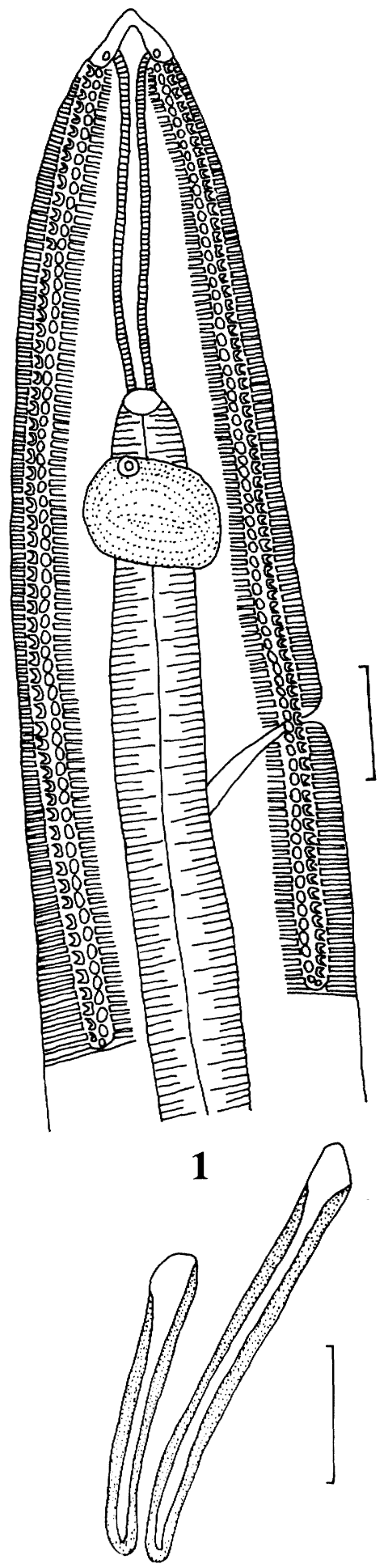

4

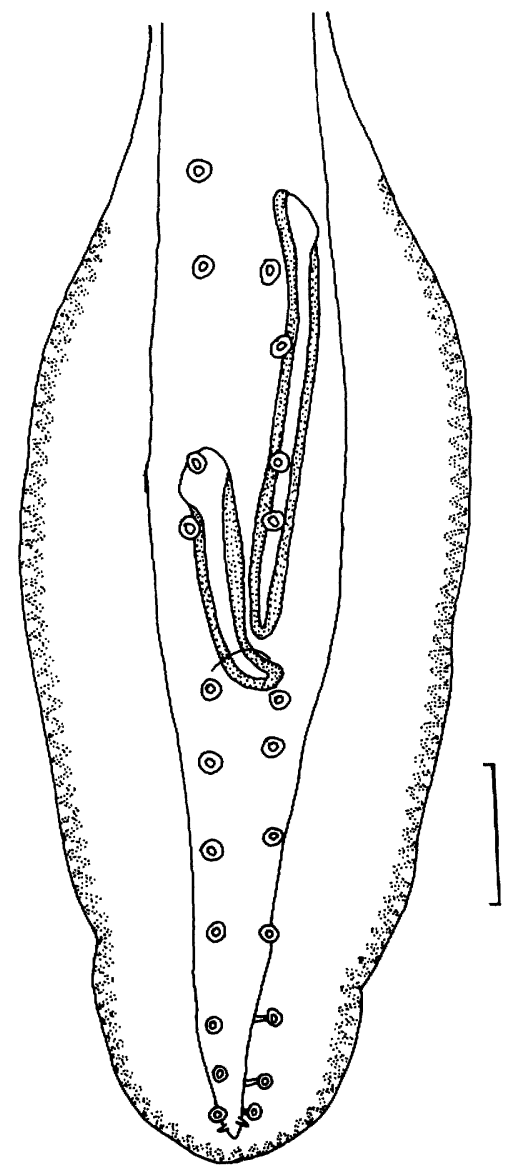

2

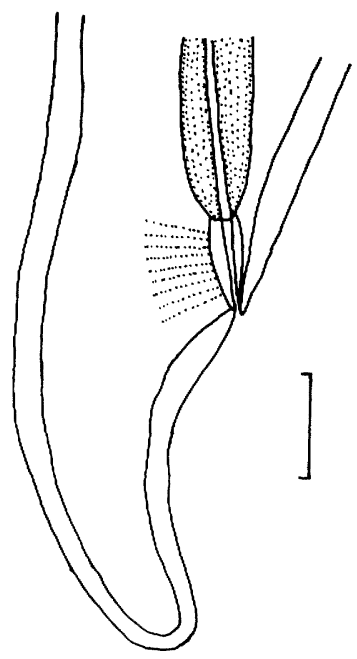

5
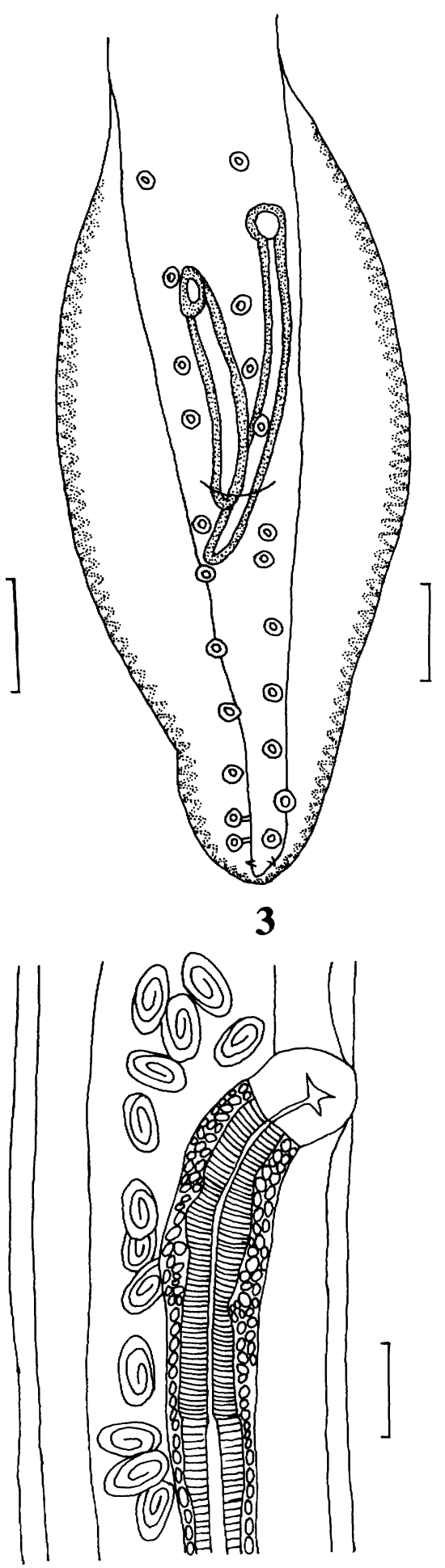

6

FiguRes 1-6. Acuaria mayori Lent, Freitas and Proenca, 1945. 1. Anterior region of female, lateral view. 2-3. Posterior end of male, ventral view. 4. Spicules. 5. Posterior end of female, lateral view. 6. Vulva region of female, lateral view. Bars $=50 \mu \mathrm{m}$. 
1,254 (975) long and 48-87 (74) wide. Nerve ring 200-247 (227) from anterior end, excretory pore 292-353 (329) from anterior end, and cervical papillae 205-258 (227) from anterior end. Didelphic. Vulva near the middle of body, $6.74-10.37 \mathrm{~mm}$ $(9.31 \mathrm{~mm})$ from anterior end, 46-58.4\% (49.6\%) TBL from anterior end. Tail short and rounded, 129-179 (148) long. Eggs ellipsoid, thick shelled, embryonated, 31.3-38.6 (34.0) long by 18.4-23.9 (20.6) wide.

\section{Taxonomic summary}

Host: Myiarchus nuttingi (Aves: Passeriformes: Tyrannidae). Localities: Cafetal, Sector Santa Rosa, ACG, Guanacaste Province, Costa Rica, $10^{\circ} 51^{\prime} 19^{\prime \prime} \mathrm{N}, 85^{\circ} 36^{\prime} 39^{\prime \prime} \mathrm{W}$. Quebrada Costa Rica, Sector Santa Rosa, ACG, Guanacaste Province, Costa Rica; $10^{\circ} 49^{\prime} 39^{\prime \prime} \mathrm{N}, 85^{\circ} 38^{\prime} 12^{\prime \prime} \mathrm{W}$, new locality.

Site of infection: Under the lining of the gizzard.

Prevalence: Forty percent ( 2 of 5 birds).

Intensity: Two males and 9 females in 1 host, and 5 males and 1 female in the second host.

Voucher specimens: USNPC 93584, 93585.

\section{Remarks}

Acuaria mayori Lent, Freitas and Proenca, 1945, was first described in Cyanocorax chrysops (Vieillot, 1818) from Paraguay and has since been reported in Sporophila caerulescens caerulescens (Vieillot, 1823) and Cyanocorax cyanomelas (Wied, 1821) from Brazil (Pinto et al., 1993, 1997). The present specimens are similar to $A$. mayori in cordon length, number and arrangement of male caudal papillae, and spicule shape but differs from the original description and previous reports by having a spicule ratio of $1: 1.5-1.7$ versus $1: 1.43-1.47$, as well as shorter spicules (left spicule 163-186 vs. 190-230; right spicule $102-123$ vs. $130-160)$ and female tails (129-179 vs. 170-230). This is the first report of A. mayori from Costa Rica, and $M$. nuttingi is a new host record.

\section{Acuaria wangi $\mathrm{n} . \mathrm{sp}$.}

(Figs. 7-11)

Diagnosis: Body small with transverse striations. Two pseudolabia lateral to mouth, each bearing a pair of large cephalic papillae and 1 inconspicuous amphid. Cordons straight, nonanastomosing, and nonrecurrent, originating at dorsal and ventral sides of oral opening, continuing posteriorly to anterior part of glandular esophagus, 15.5-19.8\% TBL. Buccal capsule long and slender, transversely striated. Esophagus clearly divided into short anterior muscular part and long posterior glandular part. Muscular esophagus $10.5-11.5 \%(11 \%)$ TBL in male and $6.7-10.3 \%(8.3 \%)$ TBL in female; glandular esophagus 26.5 $29.3 \%(28.1 \%)$ TBL in male and $15.5-27.7 \%(19.7 \%)$ TBL in female. Nerve ring located at level of anterior end of muscular esophagus. Cervical papillae immediately anterior to nerve ring. Excretory pore posterior to nerve ring.

Male $(n=4)$ : Body length 4.212-4.884 mm (4.645 mm). Maximum width 133-185 (170). Cordons 786-951 (868) long. Buccal capsule 137-156 (146) long. Muscular esophagus 486524 (511) long and 30-53 (41) wide; glandular esophagus 1.159-1.425 mm (1.306 mm) long and 76-99 (86) wide. Nerve ring 182-205 (198) from anterior end, excretory pore 263-285
(273) from anterior end, and cervical papillae 148-171 (159) from anterior end. Caudal alae well developed, 247-285 (271) long, and 32-37 (34) wide. Tail bluntly rounded, 133-152 (143) long. Ten pairs of caudal papillae, 4 pairs of preanal and 6 pairs of postanal papillae ( 1 male had only 4 pairs of postanal papillae) (Fig. 9). Postanal papillae divided into 2 groups, each group includes 3 pairs of papillae (Fig. 8). Spicules subequal but dissimilar. Left spicule long and slender, 190-209 (199) long, 9.7-12.9 (10.9) wide at base of proximal end, with a pointed distal end. Right spicule short and thick, 103-129 (116) long, 16.1-22.5 (18.9) wide at base of proximal end, with a rounded distal end. Ratio of right spicule:left spicule 1:1.6-1.8 (1:1.7).

Female $(n=9)$ : Body length $6.80-10.04 \mathrm{~mm}(8.59 \mathrm{~mm})$. Maximum width 205-311 (251). Cordons 1.26-1.85 mm (1.55 $\mathrm{mm}$ ) long. Buccal capsule 144-190 (162) long. Muscular esophagus 623-844 (711) long and 49-65 (53) wide; glandular esophagus $1.48-1.88 \mathrm{~mm}(1.69 \mathrm{~mm})$ long and 72-103 (83) wide. Nerve ring 197-266 (224) from anterior end, excretory pore 293-380 (324) from anterior end, and cervical papillae 171-228 (201) from anterior end. Didelphic. Vulva just posterior to middle of body, $3.56-5.64 \mathrm{~mm}(4.63 \mathrm{~mm})$ from anterior end, 51-57\% (54\%) TBL from anterior end. Tail short and rounded, 141-179 (157) long. Eggs ellipsoid, thick shelled, embryonated, 31-37 (36) long by 18-22 (20) wide.

\section{Taxonomic summary}

Type host: Hylophylax naevioides (Aves: Passeriformes: Formicariidae).

Other host: Gymnopithys leucaspis (Aves: Passeriformes: Formicariidae).

Type locality: Estación San Gerardo, San Gerardo, ACG, Guanacaste Province, Costa Rica; $10^{\circ} 52^{\prime} 50^{\prime \prime} \mathrm{N}, 85^{\circ} 23^{\prime} 21^{\prime \prime} \mathrm{W}$.

Site of infection: Under the lining of the gizzard.

Prevalence: In $H$. naevioides, $17.4 \%$ (4 of 23 birds). In $G$. leucaspis, $14.3 \%$ ( 1 of 7 birds).

Intensity: Range in H. naevioides, 1-4; in G. leucaspis, 2.

Type specimens: Holotype, USNPC 93544; allotype, USNPC 93545; paratypes, USNPC 93546, 93547, 93548, 93549, 93550.

Etymology: The new species is named after Professor Puqing Wang, Laboratory of Parasitology, Fujian Normal University, People's Republic of China, for his contribution to the fauna and taxonomy of nematodes.

\section{Remarks}

By having cordons extending posteriorly to the anterior portion of the glandular esophagus, A. wangi resembles A. alii Rasheed, 1960, in Acridotheres ginginianus (Latham, 1790) from India, A. crami Rasheed, 1960, in Saxicola caprata caprata (Linnaeus, 1766) from India (probably not the correct host identification as $S$. c. caprata occurs only in Luzon, Philippines), A. cyanocitta (Boyd, 1956) in Cyanocitta cristata (Linnaeus, 1758) from the United States, A. minuta Williams, 1929, in Quiscalus quiscala aeneus (this host record is also doubtful because $Q$. q. aenus (Linnaeus, 1758) is not a valid name and authority combination; $Q$. q. quiscala (L., 1758) is the type by tautonomy, and $Q$. aeneus Ridgway, 1869 , has been synonymized with $Q$. q. versicolor (Vieillot, 1819) from the 

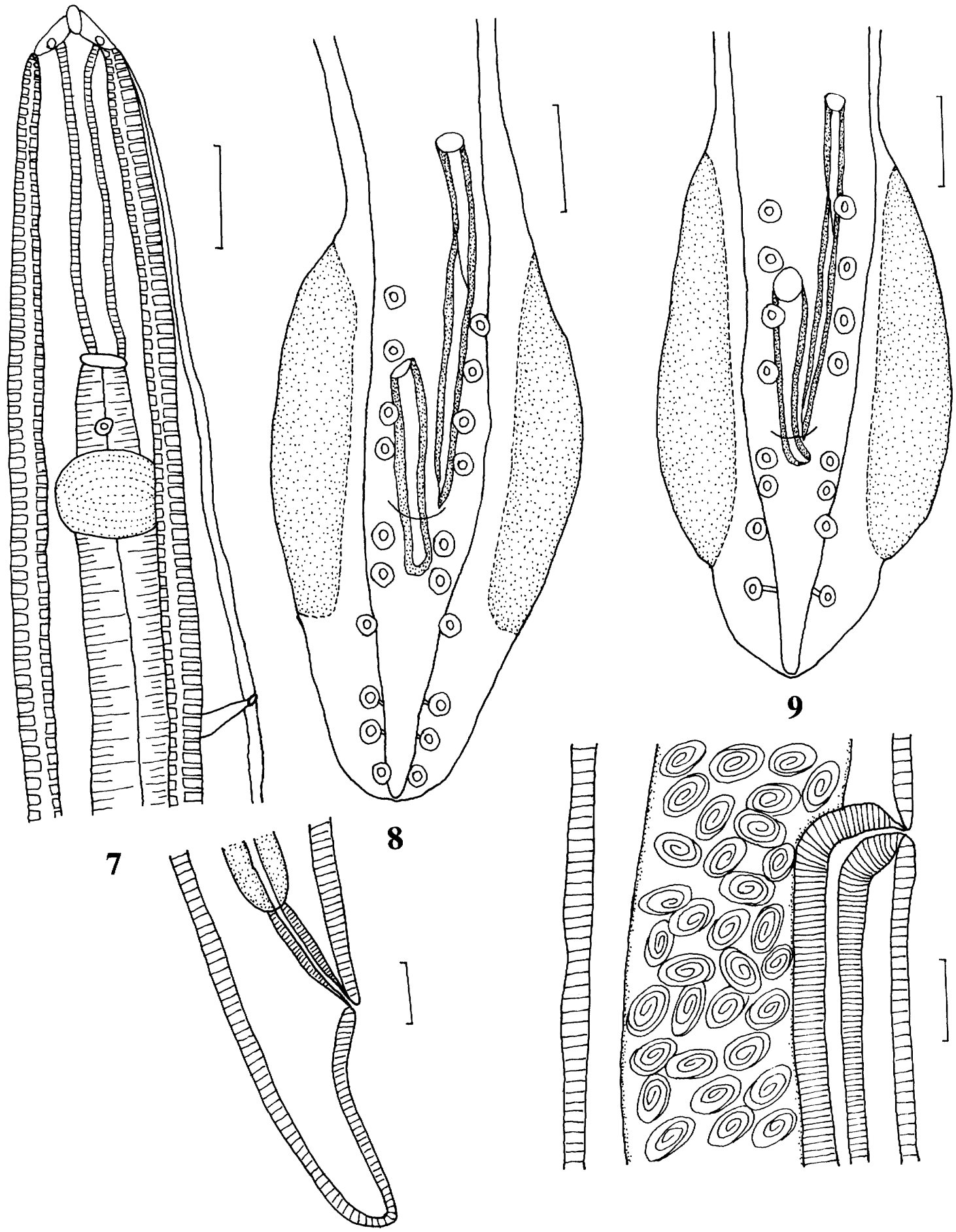

10

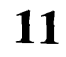

FiguRes 7-11. Acuaria wangi n. sp. 7. Anterior region of female, lateral view. 8-9. Posterior end of male, ventral view. 10. Posterior end of female, lateral view. 11. Vulva region of female, lateral view. Bars $=50 \mu \mathrm{m}$.

United States, A. pattoni Williams, 1929, in Sturnella neglecta (Audubon, 1844) from the United States, and A. cissae Wang, 1976, in Cissa e erythrorhyncha (Boddaert, 1783) from China. Other members of the genus either have very short cordons, extending to the part of muscular esophagus, or longer cordons, extending behind the glandular esophagus or to the posterior part of body.

The new species, however, differs from A. alii in having 4 pairs of preanal and 6 pairs of postanal rather than 2 pairs of preanal and 7 pairs of postanal papillae, a longer left spicule 
(190-209 vs. 110), a different spicule ratio (1:1.6-1.8 vs. 1: 1.1 ), and a right spicule with a blunt rather than pointed distal end. The new species can be distinguished from A. crami and A. minuta by its possession of 6 pairs of postanal papillae and a different spicule ratio (1:1.6-1.8 vs. $1: 1.3$ in $A$. crami and 1: 1.1 in $A$. minuta); in addition, $A$. minuta has spatulate-shaped spicules and a tricuspid-shaped distal end of the right spicule. The remaining 3 species resemble $A$. wangi by possessing 4 preanal and 6 postanal papillae. Of these, the new species can be distinguished from $A$. pattoni by having a longer left spicule (190-209 vs. 156) and a spicule ratio of $1: 1.6-1.8$ versus $1: 1$ and from A. cissae by having a shorter left spicule (190-209 vs. 268-280) and a spicule ratio of $1: 1.6-1.8$ versus $1: 2.5-2.7$. Acuaria wangi is related to A. cyanocitta, which has similarly shaped spicules, including a very pointed distal end of the left spicule and a similar spicule ratio (1:1.6-1.8 vs. $1: 1.4-1.6)$, but the new species differs in body length (male $4.2-4.9 \mathrm{~mm}$ long and female $6.8-10.0 \mathrm{~mm}$ long in A. wangi vs. male $7.5-10.0$ $\mathrm{mm}$ long and female $12.8-18.4 \mathrm{~mm}$ long in A. cyanocitta), in having shorter spicules (left spicule 190-209 vs. 315-370; right spicule $103-129$ vs. $220-230$ ), in the arrangement of postanal papillae ( 2 groups vs. 3 groups), and in having smaller eggs (31-37 long by 18-22 wide vs. 42 long by 24 wide).

\section{DISCUSSION}

Acuaria mayori was collected only from dry forest sites (Cafetal, Quebrada Costa Rica), whereas A. wangi occurred in a wet forest site (Estación San Gerardo). These are sites with abundant running water and associated riparian vegetation. Acuaria mayori was collected at the beginning of the wet season ( 5 and 7 June 2001), whereas $A$. wang $i$ was collected at the beginning of the wet season (13-14 June 2001 in $H$. naevioides and $G$. leucaspis) and at the beginning of the dry season (13 January 2002 in $H$. naevioides).

\section{ACKNOWLEDGMENTS}

We are grateful to the scientific and technical staff of the ACG for supporting this study, in particular, Elda Araya, Roger Blanco, Carolina Cano, Maria Marta Chavarría, Felipe Chavarría, Roberto Espinoza, Dunia Garcia, Guillermo Jimenez, Elba Lopez, Sigifredo Marin, Alejandro Masis, Calixto Moraga, Fredy Quesada, and Petrona Rios. Thanks are also due to Dan Janzen and Winnie Hallwachs, scientific advisers to the ACG, for their support. Host specimens were collected by D.C., Jeremiah Trimble (Museum of Comparative Zoology (MCZ)), and Calixto Moraga (ACG) under the authority of CITES (Commission on International Trade in Endangered Species) Permit US9258251, CITES Permit CR9123440, Costa Rica Ministero del Ambiente y Energia Licencia 203640283 and Resoluciones 215-2001-OFAU and 4112001-OFAU, Harvard University IACUC Protocol 21-09, and U.S. Department of Agriculture Animal and Plant Health Inspection Service Permit 47956 (Form VS16-6A). Host necropsy and parasite collections were made by D.R.B., D.C., Elda Araya, Sara Brant, Marie Causey, Ben Hanelt, Calixto Moraga, and Petrona Rios. This study was funded by a research grant from the Natural Sciences and Engineering Research Council of Canada to D.R.B. and by a grant from the MCZ Putnam Expedition Fund to D.C.

\section{LITERATURE CITED}

BREMSER, J. G. 1811. Nachricht von einer betrachtlichen Sammlung thierischer Eingeweidewurmer. etc. k. k. Naturalienkabinets. Direktion in Wien. S. 51.

Chabaud, A. G. 1975. Keys to the genera of the order Spirurida. Part 2. Spiruroidea, Habronematoidea and Acuarioidea. In $\mathrm{CIH}$ keys to the nematode parasites of vertebrates. No. 3, R. C. Anderson, A. G. Chabaud, and S. Willmott (eds.). Commonwealth Agricultural Bureaux, Farnham Royal, U.K., p. 29-58.

, AND A. PETTER. 1961. Nematodes du genre Acuaria de la faune de France. Annales de Parasitologie humaine et Comparee 36: 409-424.

CRAM, E. 1927. Bird parasites of the nematode suborders Strongylata, Ascaridata and Spirurata. United States National Museum Bulletin 140: $1-465$.

Gupta, S. P., AND M. JEHAN. 1972. On some species of the genus $A c$ uaria Bremser, 1811 from avian hosts from Lucknow. Japanese Journal of Parasitology 21: 365-373.

- AND P. KUMAR. 1977. On some species of the genus Acuaria Bremser, 1811 from avian hosts from Uttar Prasesh. Indian Journal of Helminthology 29: 120-136.

Hsu, W. N. 1963. Studies on some parasitic nematodes of order Spirurida Chitwood, 1933. Acta Zoologica Sinica 15: 544-552. [In Chinese.]

ILYAS, R. 1980. On a new species of Acuaria Bremser, 1811 from Gullus domesticus. Revista di Parasitologia 41: 73-76.

Mawson, P. M. 1972. The genus Acuaria Bremser (Nematoda: Spirurida) in Australia. Transactions of the Royal Society of South Australia 96: $139-147$.

Pinto, R. M., J. J. Vicente, AND D. Noronha. 1997. Nematode parasites of Brazilian corvid birds (Passeriformes): A general survey with a description of Viktorocara braziliensis n. sp. (Acuariidae, Schistorophinae). Memorias do Instituto Oswaldo Cruz 92: 209-214. , AND S. P. DE FABIO. 1993. New records of the nematodes Ascaridia columbae (Gmelin) Travassos, Acuaria mayori Lent, Freitas and Proenca and Aproctella stoddardi Cram in Brazilian birds, with redescription of the species. Revista Brazileira de Zoologia 8: 1-6.

SHERWIN, F. J., AND G. D. SCHMIDT. 1988. Helminths of the Mountains of Colorado, including Acuaria coloradensis n. sp. Journal of Parasitology 74: 336-338.

Skrjabin, K. I., A. A. Sobolev, And V. M. Ivashrin. 1965. Principles of Nematology 14. Spirurata of animals and man and the diseases caused by them. Part 3. Acuarioidea Izdatel'stvo Nauka, Moscow, Russia. p. 31-132. [In Russian.]

WANG, P. 1976. Notes on some new nematodes of suborder Spirurata from Fujian, China. Acta Zoologica Sinica 22: 393-402. [In Chinese.]

ZhANG, L. P. 1990. Three new species of Acuarioidea from birds from Fujian, China. Sichuan Journal of Zoology 9: 1-5. [In Chinese.] , AND Z. Y. WANG. 1993. A new species of Acuarioides from birds (Spirurida: Acuariidae). Sichuan Journal of Zoology 12: $1-$ 3. [In Chinese.] 